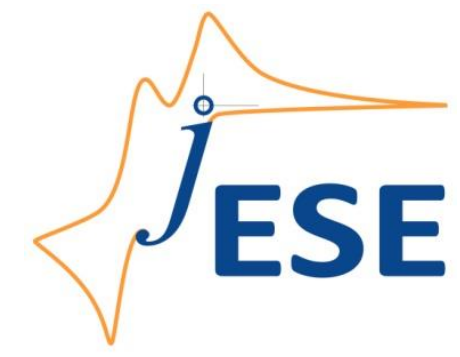

Open Access : : ISSN 1847-9286

www.jESE-online.org

Original scientific paper

\title{
$p$-toluene sulfonic acid doped polyaniline carbon nanotube com- posites: synthesis via different routes and modified properties
}

\author{
ASHOK K. SHARMA ${ }^{\varpi}$ and YASHPAL SHARMA* \\ Department of Materials Science \& Nanotechnology, D.C.R University of Science \& Technology, \\ Murthal-131 039 (Haryana) India \\ *Department of Chemistry, G. J. University of Science \& Technology, Hisar-125001, India \\ $\bowtie$ Corresponding Author: E-mail: aksharma210@gmail.com
}

Received: October 8, 2012; Revised: December 25, 2012; Published: : April 19, 2013

\begin{abstract}
Composites of polyaniline and carbon nanotube (CNT) were prepared by in-situ chemical polymerization method using various aniline concentrations in the initial polymerization solution with p-toluene sulfonic acid (PTS) as secondary dopant and mechanical mixing of the PANI and CNT using different weight ratios of PANI and CNTs. The structural characterizations of the composites were done by Fourier transform infrared (FTIR) and Ultra violet visible spectroscopy (UV-Visible). Scanning electron microscopy (SEM) was used to characterize the surface morphology of the composites. It was found that the composites prepared by in-situ chemical polymerization had smoother surface morphology in comparison to the composites obtained by mechanical mixing. The capacitive studies reveal that the in-situ composite has synergistic effect and the specific capacitance of the composite calculated from cyclic voltammogram (CV) was $385.1 \mathrm{~F} / \mathrm{g}$. Thermal studies indicate that the composites are stable as compared to PANI alone showing that the CNT contributes towards thermal stability in the PANI-CNT composites.
\end{abstract}

\section{Keywords}

Cyclic voltammetry; TGA; scanning electron microscopy; composites; conducting polymer; specific capacitance; chemical polymerization; doping, nanomaterials.

\section{Introduction}

Due to exceptional electrical, electronic and mechanical properties, conducting polymers are also popular as synthetic metals. Various conducting polymers such as polyaniline, polyacetylene, polypyrrole and polythiophene have been the subject of intensive research because of their application in different fields such as optoelectronic and display devices, and as active electrode materials in primary and secondary batteries, supercapacitors, tissue engineering, drug delivery etc $[1,2]$. 
Carbon nanotubes after their discovery by lijima and Ichihashi [3] have been the field of great interest because of their unique electronic, mechanical and magnetic properties [4]. Owing to their unique properties there are varieties of applications of CNT which include supercapacitors and batteries, sensors, biological applications like bone tissue engineering and many more [5]. Recently, composites of the CNT and conducting polymers were a matter of immense research because the composite from these two important materials produce the synergistic effect and produce better applications than the individual materials [6-9]. CNT acts as good filler in the polymer composite compared to other carbon materials because of their high surface area. Various conducting polymers have been investigated to be used in the composite preparation but out of these PANI acts as promising material because of its various properties like air stability, flexibility, light weight, high conductivity, ease of synthesis by chemical and electrochemical method and good processability $[10,11]$. Recently, PANI was investigated in the synthesis of PANICNT composites by using MWNT [7,9], SWNT [8] and carboxylated CNT [6,12].

The composite preparation from the PANI and CNT produces a hybrid material having great mechanical strength, high capacitance properties, electrical properties and good processability [13-16]. There are mainly two methods to prepare such composites: chemical oxidative polymerization method and the electrochemical method. The electrochemical method has limitations in terms of mass production while chemical method gives a high yield and is cheaper [17].

Doping plays an important role in the conducting polymers. Doping is the process which converts the neutral polymer backbone to a charged $\pi$ conjugated system. This allows electrons to flow through $\pi$ conjugated system of the conducting polymers due to the formation of conduction bands. Various dopant are used for doping of polyaniline which include $p$-toluene sulphonic acid (PTS), dodecyl benzenesulphonic acid (DBSA), camphor sulphonic acid (CSA), polyvinyl sulfonic acid (PVA) etc. [18]. However, $\mathrm{HCl}$ itself acts as a dopant for PANI but using a secondary dopant along with $\mathrm{HCl}$ enhance the electronic properties of the material and also the processability.

This study describes the synthesis of some PANI-CNT composites using $p$-toluene sulfonic acid (PTS) as secondary dopant along with $\mathrm{HCl}$ by means of chemical oxidative polymerization method and by mechanical mixing of the PTS doped PANI and CNT in the same proportions as used in the in-situ chemical oxidative polymerization. The synergistic capacitive effect of the composite was also investigated. The difference in the morphology and thermal behaviour of the composites prepared by both the methods were also investigated.

\section{Experimental}

\section{Materials}

MWNT (99\%) was purchased from Nanostructured and Amorphous Materials Inc. having outer diameter 20-40 $\mathrm{nm}$ and length of 1-2 $\mu \mathrm{m}$. Aniline (S.D. Fine-Chem. Ltd, $99.5 \%$ ) was vacuum distilled prior to use. PVDF, MW Vaco Carbon and $p$-toluene sulfonic acid (PTS) sodium salt (95\%) was purchased from Sigma-Aldrich. All other chemicals like hydrochloric acid (35.4\%), ammonium peroxydisulfate (APS) (98\%), ethanol (99.9\%), sulphuric acid (98\%), activated carbon and $\mathrm{N}, \mathrm{N}$-dimethyl formamide (DMF) were obtained from S.D. Fine Chem. Ltd. and used as received without further purification. All chemicals were of analytical grade. Solutions were prepared in deionized water. 
Preparation of PANI-CNT composites by in-situ chemical polymerization

For the preparation of PANI-CNT composites by in-situ chemical oxidative polymerization method $0.5 \mathrm{~g}$ of CNT was dissolved in $1 \mathrm{M} \mathrm{HCl}$ and then ultrasonicated for 2 hours in order to disperse CNT bundles. Different amounts of aniline monomer $(0.5,1.5,2.5,3.5$ and $4.5 \mathrm{ml}$ yielding CNT: Aniline ratios of 1:1, 1:3, 1:5, $1: 7$ and 1:9, wt/v) was dissolved in $1 \mathrm{M} \mathrm{HCl}$ and $0.2 \mathrm{M} \mathrm{PTS}$. This content was transferred to the flask containing ultrasonicated CNT. Again the mixture (CNT+Aniline) was put to ultrasonication for 2 hours, to incorporate aniline monomer in the CNT matrix. A freshly prepared pre-cooled ammonium peroxydisulphate $(1 \mathrm{M})$ solution in $1 \mathrm{M} \mathrm{HCl}$ was added drop wise to the CNT-aniline mixture. The reaction mixture was stirred for 6 hours at $0-5^{\circ} \mathrm{C}$. Appearance of greenish black color indicated the formation of the PANI-CNT composite. The resulting solution was filtered and washed with distilled water and methanol several times to remove the unreacted oxidant and oligomers if any. The product was dried in vacuum oven at $60{ }^{\circ} \mathrm{C}$ overnight. PANI was also prepared as above where $2.5 \mathrm{ml}$ of aniline was dissolved in the initial polymerization solution. Herein, the PANI-CNT composites with different ratios of CNT and aniline monomer will be designated as ratios of CNT: aniline monomer given in parentheses: CPC1 (1:1), CPC2 (1:3), CPC3 (1:5), CPC4 (1:7), CPC5 (1:9). Figure 1 is the schematic representation of the in-situ chemical oxidative polymerization method.

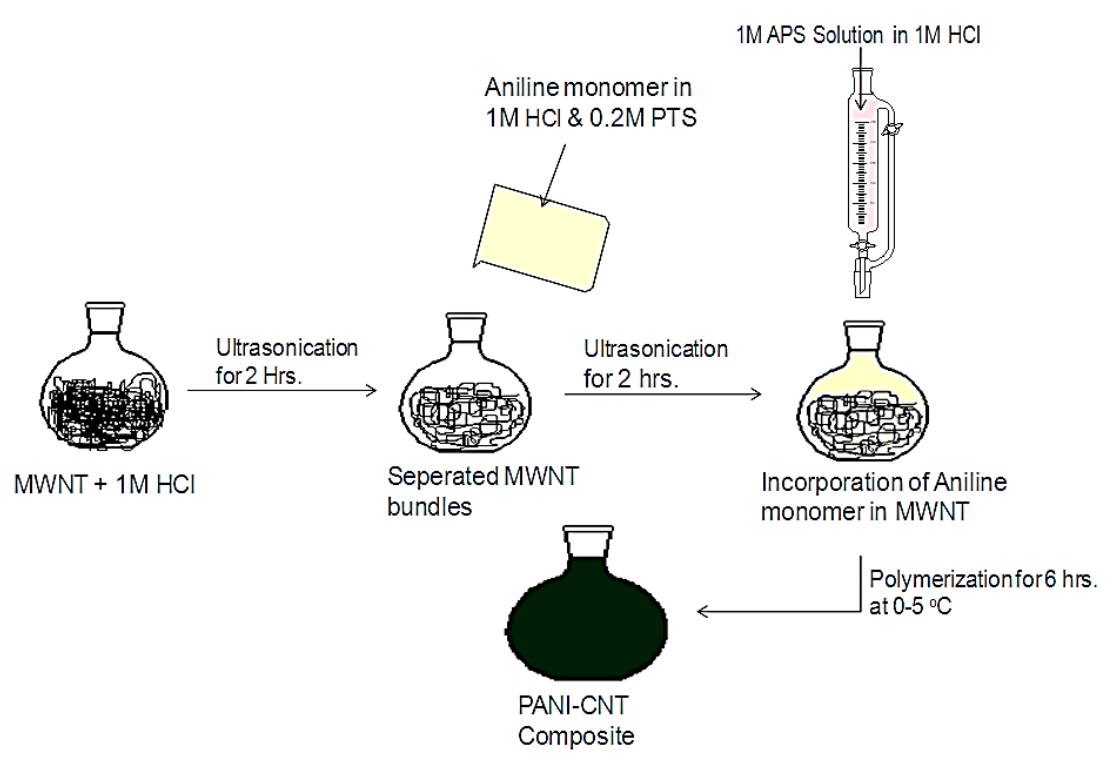

Figure 1. Schematic representation of the in-situ chemical oxidative polymerization method

\section{Preparation of PANI-CNT composites by mechanical mixing method}

For the preparation of PANI-CNT composites by mechanical mixing method, PANI was prepared by the in-situ chemical route. The as such prepared PTS doped PANI was mixed with CNT in different ratios (CNT:PANI ratios were 1:1, 1:3, 1:5, 1:7 and 1:9) in DMF solvent. The mixture was ultrasonicated for 2-3 hours to disperse the CNT bundles and for better incorporation of the CNT in the polymer matrix. After sonication the mixture was magnetically stirred for 6-7 hours. Finally, the mixture was filtered and washed several times with distilled water and methanol. The PANICNT composites were collected by drying the powder in vacuum oven at $60{ }^{\circ} \mathrm{C}$. Herein, the PANICNT composites prepared by mechanical mixing method with different ratios of CNT and PANI will be designated as ratios of CNT: PANI given in parentheses CPM1 (1:1), CPM2 (1:3), CPM3 (1:5), CPM4 (1:7), CPM5 (1:9). 


\section{Preparation of electrode for cyclic voltammetry}

The PANI-CNT composite prepared by in-situ chemical oxidative polymerization method was mixed with 10 wt. \% of activated carbon and 5 wt. \% of MW Vaco Carbon as conductor and 5 wt. \% of binder (PVDF) in N,N-Dimethyl formamide (DMF) solvent. The mixture was ultrasonicated for 2 hours and then stirred to form slurry. The slurry was brush coated on $2 \times 2 \mathrm{~cm}^{2}$ of graphite sheet as a current collector.

\section{Characterization}

The chemical structure of the composite was characterized by using Fourier transform infrared spectrophotometer (Shimadzu IR Affinity-I 8000 FT-IR spectrophotometer). Interaction between PANI and CNT was investigated by means of UV-Visible spectroscopic technique (Varian Cary- 5000 spectrophotometer). The scanning electron microscopy (SEM, JEOL-JSM-5600LV) was used to examine the surface morphology and average thickness of deposited PANI over the surface of CNT. The capacitive property of the PANI-CNT composite electrodes was examined by cyclic voltammetry using three-electrode cell system with a reference electrode (saturated calomel electrode) and a counter electrode (Pt) in $1 \mathrm{M} \mathrm{H}_{2} \mathrm{SO}_{4}$ solutions as electrolyte. Cyclic voltammetry measurements were carried out by potentiostat/galvanostat ( $\mathrm{CH}$ Instruments $600 \mathrm{C}$ series). The geometric surface area of the working electrode was $2 \times 2 \mathrm{~cm}^{2}$. Cyclic voltammograms were recorded in the voltage windows $0-0.8 \mathrm{~V}$ at a scan rate of $2 \mathrm{mV} / \mathrm{s}$. Thermal analyses of the CNT, PANI and PANICNT composites was done by using thermogravimetric analyzer (Universal V4.7A TA Instruments).

\section{Results and Discussion}

\section{FTIR study}

The FTIR spectrum of the PANI-CNT composite is given in Figure 2. The spectrum shows all bands of PANI. The band at 1448.58 and $1581.16 \mathrm{~cm}^{-1}$ may be assigned to the benzoid and quinoid ring vibrations, respectively. The band at $1294.11 \mathrm{~cm}^{-1}$ is due to the conducting form of the PANI indicating that the PANI exists in the conducting emeraldine salt form. The bands at 1100.79 and $785.68 \mathrm{~cm}^{-1}$ may be assigned to the aromatic $\mathrm{C}-\mathrm{H}$ in plane and aromatic $\mathrm{C}-\mathrm{H}$ out of plane bending vibrations, respectively [19]. A broad peak at $3402.13 \mathrm{~cm}^{-1}$ is due to the $\mathrm{N}-\mathrm{H}$ stretching vibration of the aromatic amine. The bands at 1068.92 and $674.19 \mathrm{~cm}^{-1}$ represent the symmetric stretching of the $\mathrm{SO}_{3}{ }^{-}$group [18]. The bands are in agreement with the theoretical predictions and confirm the deposition of PANI over the surface of the CNT i.e. formation of PANI-CNT composite using PTS as secondary dopant $[20,21]$.

\section{UV-Visible spectra}

UV-Visible spectra of the CNT, PANI and the PANI-CNT composite were recorded in N,N-dimethylformamide (DMF) solvent in the wavelength range from 300 to $800 \mathrm{~nm}$. Figure 3 shows the UV-Visible spectra of CNT, PANI and the PANI-CNT composite. The CNT has no characteristic peak in this region. PANI has its characteristic peak at $540 \mathrm{~nm}$. For the PANI-CNT composite the PANI shows its characteristic peak at $541 \mathrm{~nm}$ showing the protonated doped state of the polyaniline indicating the deposition of PANI over the CNT surface and formation of composite [22,23]. 


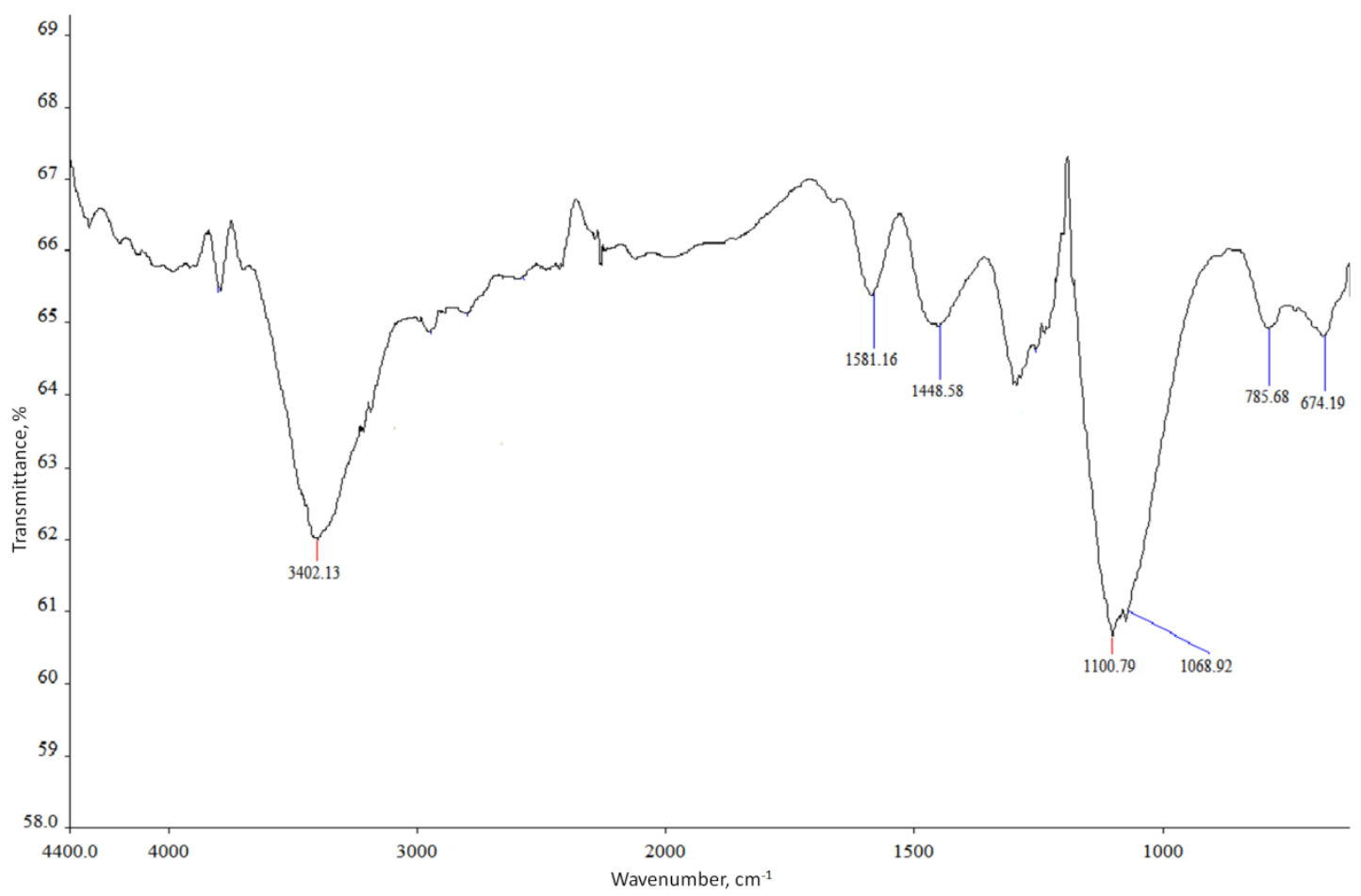

Figure 2. FTIR spectrum of the PANI-CNT composite

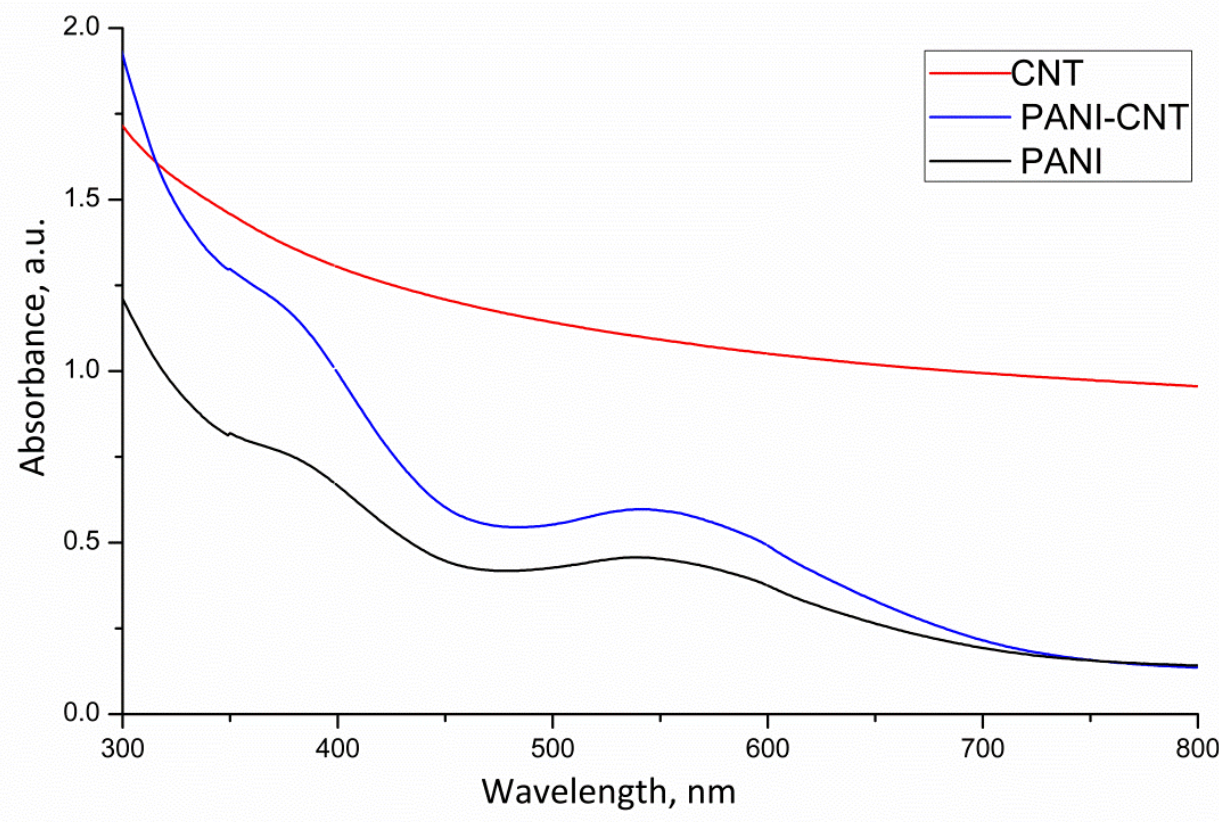

Figure 3. UV-Visible spectra of the CNT, PANI and PANI-CNT composite

\section{Surface morphology}

Surface morphology of the composites was studied by scanning electron microscopy (SEM). Figure 4a-c shows the SEM micrographs of the CNT, CPC5 and CPM5 respectively. CNT shows smooth surface morphology with average diameter of $\approx 20-40 \mathrm{~nm}$. Comparing Figure $4 \mathrm{~b}$ with the SEM micrograph of CNT (Figure 4a) it could be concluded that the polyaniline becomes deposited over the surface of the CNT indicating the formation of the PANI-CNT composite. PANI-CNT composite shows that the average thickness of deposited PANI over the surface of CNT is $\approx 200-230 \mathrm{~nm}$. Comparing Figure 4c with the SEM micrographs of CNT (Figure 4a) and the 
PANI-CNT composite (Figure $4 \mathrm{~b}$ ), it can be said that the composite prepared through mechanical mixing method shows defective and irregular surface morphology which may be caused due to mixing of the two components for long period of time. However, it it is not easy to distinguish the CNT bundles in the composite which is clearly seen in case of PANI-CNT composite prepared by insitu chemical oxidative polymerization method. In the case of the in-situ polymerization method, the PANI wrapped the CNT surface in a regular manner using each CNT bundle as can be seen in Figure $4 \mathrm{~b}$ but in mechanical mixing method the PANI deposition takes place instead of wrapping over the CNT in irregular fashion.

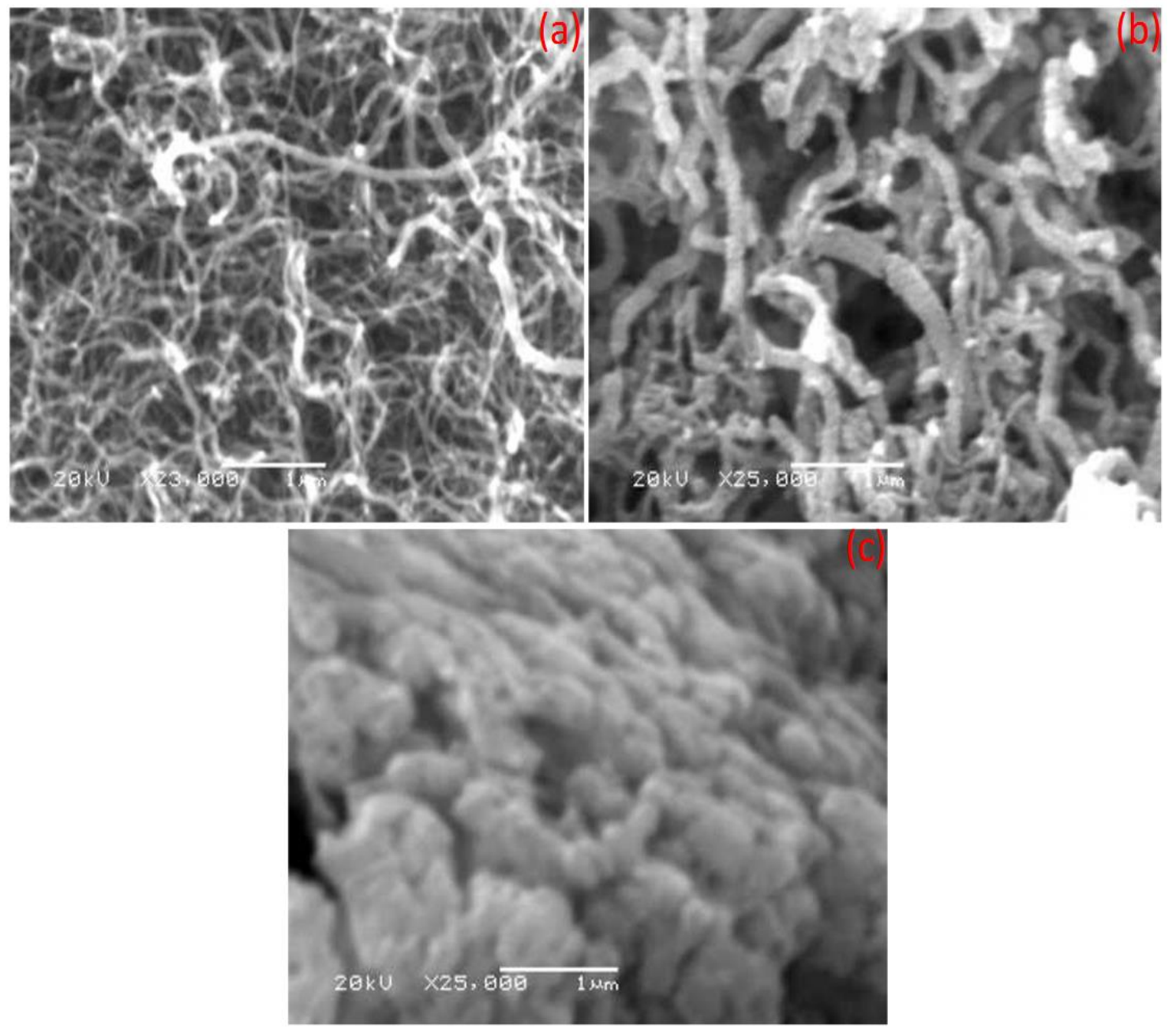

Figure 4. SEM micrographs of (a) CNT, (b) CPC5 and (c) CPM5 respectively

\section{Capacitive study}

The capacitive characteristic of the CNT, PANI and the PANI-CNT composite prepared by in-situ chemical oxidative polymerization was investigated by means of cyclic voltammetry. The capacitance was calculated from the obtained cyclic voltammogram by dividing the average current with scan rate while the specific capacitance was calculated by dividing the capacitance by the weight of active material.

It can be concluded from Figure 5 that CNT behaves like an electric double layer showing almost rectangularly shaped cyclic voltammogram and is almost mirror image with respect to zero current line. For the PANI and PANI-CNT composite the redox peaks are indicative of the higher currents flowing in the PANI-CNT as compared to the PANI alone and can be attributed to the porous structure of the composite in which CNT provides a larger surface area for aniline to polymerize 
upon. The specific capacitance of CNT, PANI and PANI-CNT composite calculated from cyclic voltammograms was $31.56 \mathrm{~F} / \mathrm{g}, 314.07 \mathrm{~F} / \mathrm{g}$ and $385.1 \mathrm{~F} / \mathrm{g}$, respectively. It can be explained as the synergy contribution from the PANI and the CNT because of better electrolyte access in the active material and improved contact between the current collector and the active material resulting in decreased overall internal resistance in the electrode and better capacitance value [24-27].

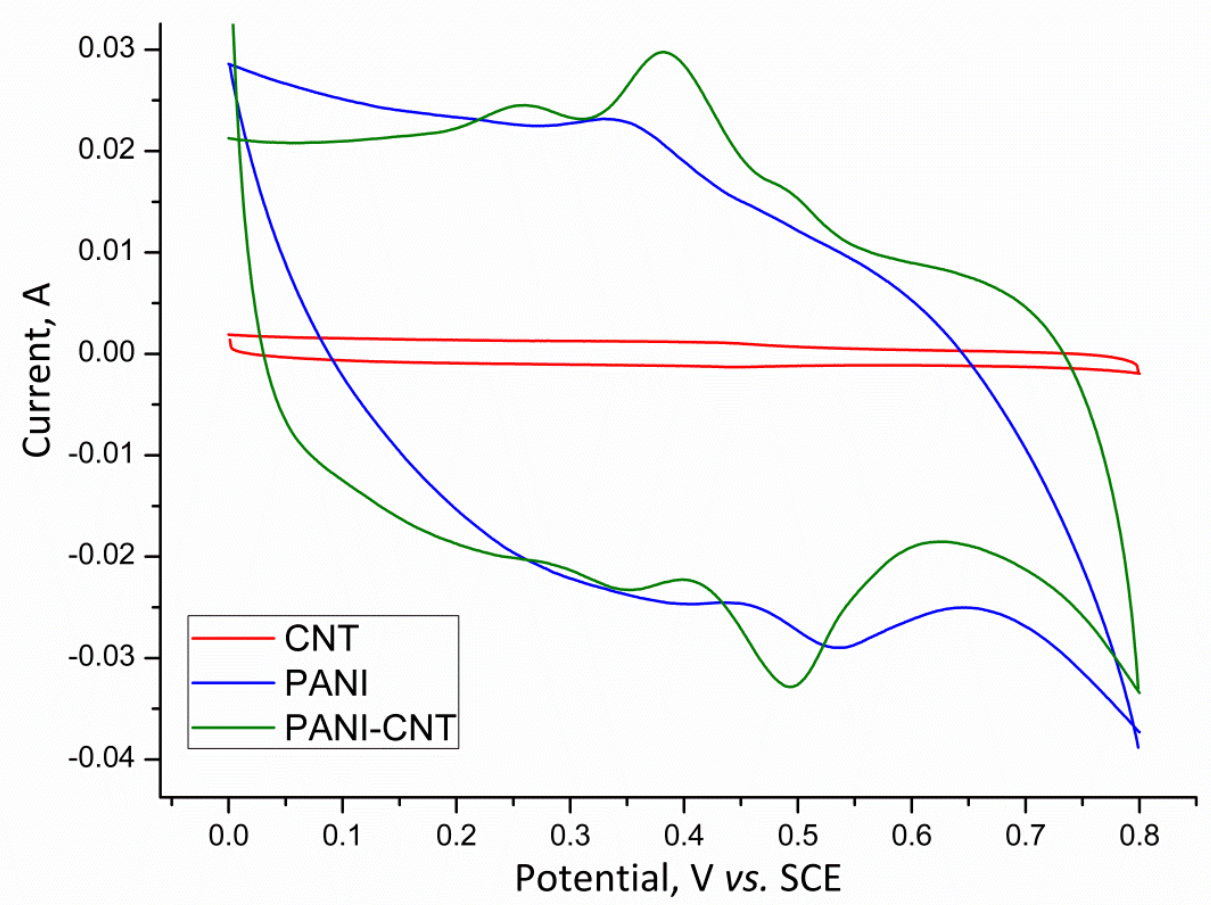

Figure 5. Cyclic voltammogram of CNT, PANI and the PANI-CNT composite

\section{Thermal analysis}

Thermogravimetric analysis (TGA) of the CNT, PANI and the CNT-PANI composites were carried out under nitrogen atmosphere in order to investigate the $\%$ mass loss with respect to temperature. Figures $6 a$ and $6 \mathrm{~b}$ show the TGAs of the CNT, PANI and CNT-PANI composites prepared by chemical and mechanical mixing method, respectively. From Figure 6a it can be inferred that the composites show very good thermal stability as compared to the PANI, which can be attributed to the presence of CNT in the original polymer matrix [22]. CNT has highest thermal stability and does not show any decomposition in the temperature range of 30 to $580{ }^{\circ} \mathrm{C}$. The polyaniline on the other hand exhibited a slight decrease in the weight at $114{ }^{\circ} \mathrm{C}$ which can be assigned to the loss of water [28]. Up to temperatures of $340{ }^{\circ} \mathrm{C}$ approximately $15 \%$ of the weight is lost. Above this temperature PANI showed regular decrease in the weight due to thermal degradation of the polymer.

The order of thermal stability of various PANI-CNT composites, prepared chemically is CPC1 $>$ CPC5 $>$ CPC4 $>$ CPC3 $>$ CPC2 indicating increased thermal stability of the composite as aniline content increases in the initial polymerization solution. Highest thermal stability of CPC1 may be assigned to 1:1 aniline to CNT ratio and hence the lesser amount of PANI. Therefore, CNT in this composite played a dominant role in promoting the thermal stability. In case of higher aniline content the thermal stability is somewhat independent to the CNT content and can be attributed to the layer by layer degradation of the deposited PANI over CNT surface. 

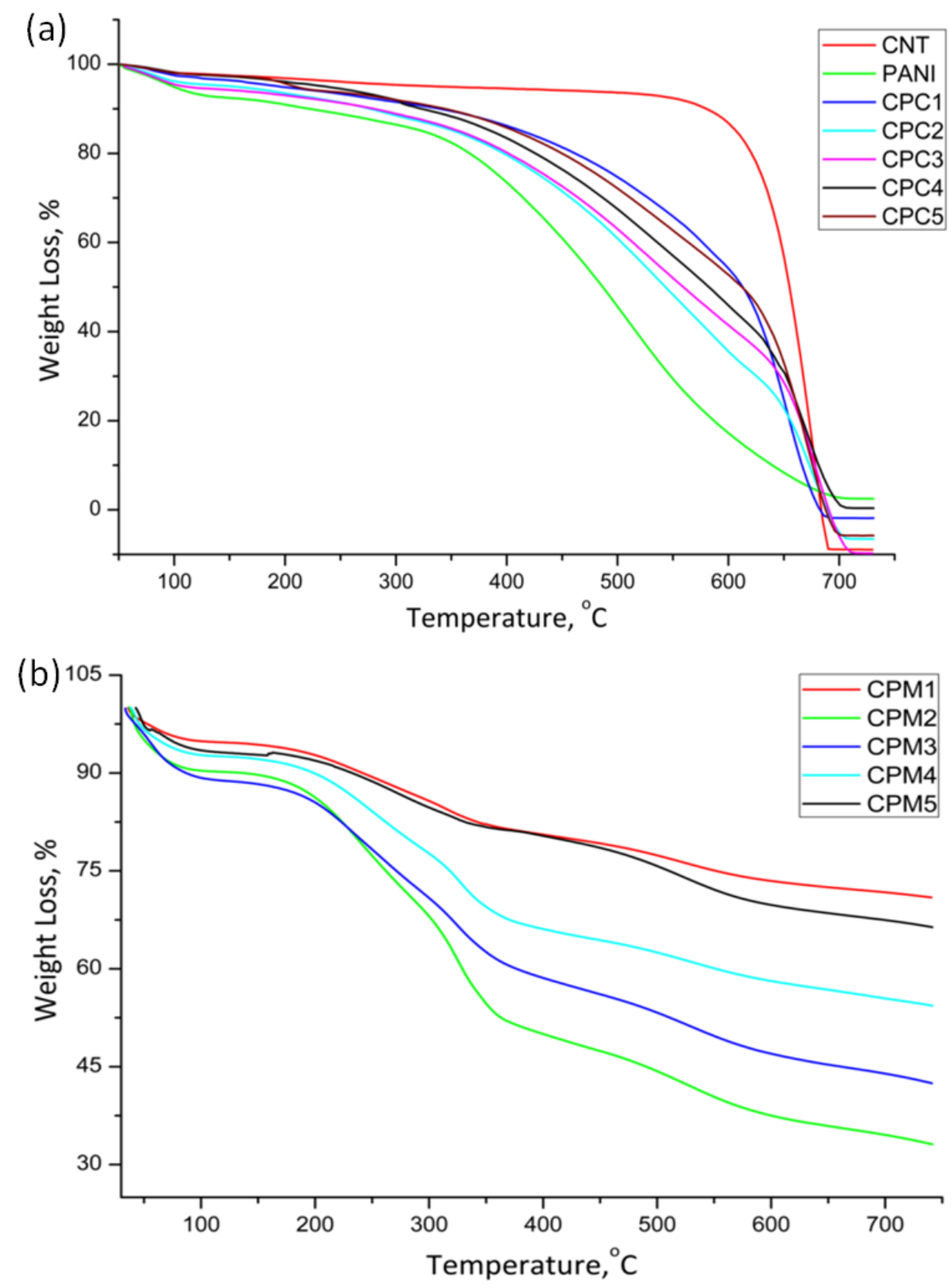

Figure 6. TGA Curves of (a) CNT, PANI and PANI-CNT composites prepared by in-situ chemical oxidative polymerization method and (b) PANI-CNT composites prepared by mechanical mixing method

Table 1. Comparison of \% weight loss of two kinds of composites at 380 and $600{ }^{\circ} \mathrm{C}$

\begin{tabular}{|c|c|c|}
\hline Composite & Weight loss at $380^{\circ} \mathrm{C}, \%$ & Weight loss at $600^{\circ} \mathrm{C}, \%$ \\
\hline CPC1 & 13 & 48 \\
\hline CPC2 & 19 & 64 \\
\hline CPC3 & 18 & 59 \\
\hline CPC4 & 15 & 56 \\
\hline CPC5 & 13 & 48 \\
\hline CPM1 & 19 & 28 \\
\hline CPM2 & 50 & 67 \\
\hline СРM3 & 41 & 55 \\
\hline CPM4 & 33 & 44 \\
\hline CPM5 & 20 & 30 \\
\hline
\end{tabular}


A similar trend was obtained for the mechanically mixed composites. For comparison purpose the weight losses of the composites at temperature $380{ }^{\circ} \mathrm{C}$ and $600{ }^{\circ} \mathrm{C}$ are given in the table I. The results revealed that the composites prepared by chemical method have higher thermal stability compared to composites by mechanical mixing at the temperature range of $380{ }^{\circ} \mathrm{C}$. This can be attributed to the layer by layer deposition of the PANI over the CNT surface in case of chemically prepared composites which can also be seen in the SEM micrograph, whereas no such layered structure is obtained in the mechanically mixed composites. The other reason behind this is the smooth surface morphology of the chemically prepared composites due to separation of the CNT bundles. However, at temperature of $600{ }^{\circ} \mathrm{C}$ the reverse order of thermal stability was seen because of presence of higher PANI content in the mechanically mixed composites [29]. Another reason is that in the case of mechanically mixed composites there is a lower chance of separation of CNT bundles and hence the PANI gets deposited over thick CNT bundles resulting in the enhanced stability at higher temperature.

\section{Conclusions}

The composites of the PANI-CNT have been successfully synthesized chemically and by mechanical mixing of the PANI and CNT. Composites prepared by chemical polymerization have smooth surface morphology indicative of layer by layer deposition of the PANI over CNT substrate. Whereas the composites prepared by mechanical mixing appear to have irregular deposition of PANI. The thermal stability of the composite is better than the PANI indicating the contribution of CNT towards the thermal stability of the composites. The composite exhibited higher value of specific capacitance than the CNT and PANI alone and is indicative of the synergy. However, CNT did not contributed much to the capacitive value but acts as a good substrate for PANI deposition.

Acknowledgements: Authors are thankful to the University Grants Commission, New Delhi (INDIA) for providing financial assistance in the form of major research project.

\section{References}

[1] J.W. Schultze, H. Karabulut, Electrochim. Acta 50 (2005) 1739-1745.

[2] Y. Sharma, A. Tiwari, S. Hattori, D. Terada, A.K. Sharma, M. Ramalingam, H. Kobayashi, Int. J. Biol. Macromol. 51 (2012) 627-631.

[3] S. lijima, T. Ichihashi, Nature 363 (1993) 603-605.

[4] J.W. Mintmire, B.I. Dunlap C.T. White, Phys. Rev. Lett. 68 (1992) 631-634.

[5] M. Tasviri, H.A. Rafiee-Pour, H. Ghourchian, M.R. Gholami, Appl. Nanosci. 1 (2011) 189195.

[6] Y.J. Zhang, Y.W. Lin, C.C. Chang, T.M. Wu, Synth. Met. 161 (2011) 937-942.

[7] R. Mangu, S. Rajaputra, V.P. Singh, Nanotechnology 22 (2011) 215502.

[8] A.A. Mikhaylova, E.K. Tusseeva, N.A. Mayorova, A.Y. Rychagov, Y.M. Volfkovich, A.V. Krestinin, O.A. Khazova, Electrochim. Acta 56 (2011) 3656-3665.

[9] L. Zheng, X. Wang, H. An, X. Wang, L. Yi, L. Bai, J. Solid State Electrochem. 15 (2011) 675681.

[10] T.A. Skotheim, R.L. Elsenbaumer, J.R. Reynolds, Handbook of conducting polymers, Marcel Dekker, New York (1997).

[11] P. Ghosh, S.K. Siddhanta, A. Chakrabarti, Eur. Polym. J. 35 (1999) 699-710.

[12] T.M. Wu, Y.W. Lin, C.S. Liao, Carbon 43 (2005) 734-740.

[13] L.S. Schadler, S.C. Giannaris, P.M. Ajayan, Appl. Phys. Lett. 73 (1998) 3842-3844. 
[14] H.D. Wagner, O. Lourie, Y. Feldman, R. Tenne, Appl. Phys. Lett. 72 (1998) 188-190.

[15] D. Qian, E.C. Dickey, R. Andrews, T. Rantell, Appl. Phys. Lett. 76 (2000) 2868-2870.

[16] S.L. Shi, L.Z. Zhang, J.S. Li, J. Polym. Res. 16 (2009) 395-399.

[17] E. Frackowiak, V. Khomenko, K. Jurewicz, K. Lota, F. Béguin, J. Power Sources 153 (2006) 413-418.

[18] P.D. Gaikwad, D.J. Shirale, V.K. Gade, P.A. Savale, K.P. Kakde, H.J. Kharat, M.D. Shirsat, Bull. Mat. Sci. 29 (2006) 417-420.

[19] M.R. Karim, C.J. Lee, Y.T. Park, M.S. Lee, Synth. Met. 151 (2005) 131-135.

[20] S.B. Kondawar, S.A. Acharya, S.R. Dhakate, Adv. Mat. Lett. 2 (2011) 362-367.

[21] B.S. Kushwah, S.C. Upadhyaya, S.Shukla, A.S. Sikarwar, R.M. S. Sengar, S. Bhaduria, Adv. Mat. Lett. 2 (2011) 43-51.

[22] T.M. Wu, Y.W. Lin, Polymer 47 (2006) 3576-3582.

[23] A.K. Sharma, Y. Sharma, Anal. Lett. 45 (2012) 2075-2085.

[24] S.R. Sivakkumar, W.J. Kim, J.A. Choi, D.R. MacFarlane, M. Forsyth, D.W. Kim, J. Power Sources 171 (2007) 1062-1068.

[25] J.H. Kim, Y.S. Lee, A.K. Sharma, C.G. Liu, Electrochim. Acta 52 (2006) 1727-1732.

[26] J.H. Kim, A.K. Sharma, Y.S. Lee, Mat. Lett. 60 (2006) 1697-1701.

[27] A.K. Sharma, Y. Sharma, R. Malhotra, J.K. Sharma, Adv. Mat. Lett. 3 (2012) 82-86.

[28] W. Feng, , X.D. Bai, Y.Q. Lian, J. Liang, X.G. Wang, K. Yoshino, Carbon 41 (2003) 1551-1557.

[29] A.M. Showkat, K.P. Lee, A.I. Gopalan, S.H. Kim, S.H. Choi, S.H. Sohn, J. Appl. Polym. Sci. 101 (2006) 3721-3729.

(C) 2013 by the authors; licensee IAPC, Zagreb, Croatia. This article is an open-access article distributed under the terms and conditions of the Creative Commons Attribution license

(http://creativecommons.org/licenses/by/3.0/) 